\title{
El negocio simulado: compraventa bajo la apariencia de donación
}

\author{
Recibido: 1 de abril de 2020 • Aprobado: 13 de julio de 2020 \\ https://doi.org/10.22395/ojum.v20n42a18
}

\author{
Grisel Galiano Maritan \\ Universidad de Guayaquil, Ecuador \\ griselgalian01986@gmail.com \\ https://orcid.org/0000-0002-5746-9171
}

\section{RESUMEN}

El artículo aborda un tema que ha adquirido gran relevancia en la práctica jurídica en Cuba por el creciente desarrollo de las relaciones contractuales y las modificaciones existentes a partir de la promulgación del Decreto-Ley 288 de 28 de octubre de 2011 -modificativo de la Ley General de la Vivienda - y el Decreto 320 de 31 de diciembre de 2013. Se trata de la simulación de los negocios jurídicos, especialmente de la compraventa bajo la apariencia de un contrato de donación que, anteriormente, por razones prohibitivas, pretendían lograrse a través de otros negocios jurídicos. El objetivo de la presente investigación es fundamentar la posible validez del contrato de compraventa simulado a partir de los supuestos doctrinales y legales existentes. El trabajo seguirá una metodología cualitativa, mediante el uso de métodos y técnicas propios de una investigación social de corte jurídico, como lo son el método histórico-lógico, el exegéticoanalítico y el de comparación jurídica. El principal resultado consiste en la propuesta de los presupuestos dogmáticos que establezcan la posible validez de la compraventa simulada, una vez declarado nulo el negocio de donación simulado que le sirvió de máscara.

Palabras clave: negocio jurídico; simulación; compraventa; donación; prueba; validez. 


\section{The Feigned Business: Sale and Purchase Under the Donation Appearance}

\section{ABSTRACT}

The article approaches a topic that has acquired great practical relevance in Cuba for the growing development of the contractual relationships and the existent modifications starting from the promulgation of the Ordinance-law n. ${ }^{\circ} 288$ of October 28th 2011 and Decree 320 of December 31st 2013: the simulation of the juridical business, especially of the sale and purchase under the appearance of a donation contract that previously, for prohibitive reasons, sought to be achieved through other juridical businesses. The objective of the present investigation is to base the possible validity of the feigned sale and purchase contract, starting from the existent doctrinal and legal suppositions. The work will follow a qualitative methodology by means of the use of methods and technical characteristic of a social investigation, of juridical type, like the historical-logical one, the exegetical-analytic and the artificial comparison methods. The main result consists of the proposal of the dogmatic budgets that establish the possible validity of the feigned sale and purchase once declared null the feigned donation business that served as a mask.

Keywords: juridical negotiation; simulation; sale and purchase; donation; proof; validity. 


\section{INTRODUCCIÓN}

El artículo que a continuación se presenta es el resultado de una investigación realizada por la autora en la Facultad de Derecho de la Universidad de la Habana (Cuba). Esta investigación fue el resultado final de su tesis de maestría en Derecho Civil sobre la simulación de los negocios jurídicos, especialmente sobre la compraventa bajo la apariencia de una donación.

Los negocios jurídicos constituyen una categoría de acto jurídico, pues ambos se derivan de una actuación humana que realizan con conciencia y voluntad. La identificación del negocio o contrato guarda estrecha relación con el principio de autonomía de la voluntad, aunque esta no es suficiente para que produzca los efectos jurídicos que por su propia naturaleza le vienen impuestos al negocio, sino que debe cumplir con los requisitos legales exigidos y las condiciones que han sido fijadas por las partes.

Los negocios jurídicos están integrados por elementos esenciales, naturales y accidentales. Los primeros son indispensables para que pueda existir el contrato, y en caso de faltar alguno de ellos, el negocio carecería de validez. Dentro de ellos se encuentran los elementos de carácter subjetivo, y los que son de carácter objetivo.

En el caso de los elementos de carácter subjetivo se reconoce la voluntad, nervio central del negocio, que como elemento esencial debe cumplir determinados requisitos, los cuales, sin orden de preferencia, son indispensables para su validez. No obstante, para que la voluntad alcance el valor jurídico requerido, es necesario que sea expresada mediante una declaración de voluntad. Esto, además, para que pueda ser conocida por la otra parte del negocio jurídico y se configure el consentimiento contractual.

De esta forma, se puede hablar de una voluntad internamente formada y de la declaración de esta. Empero, se pueden presentar inconvenientes en el caso de que no exista concordancia entre la voluntad interna con la que se declara. Esta discrepancia puede producirse inconscientemente, de forma involuntaria, o voluntariamente, formándose un supuesto de reserva mental, conocida como declaración falta de seriedad, o simulación.

La doctrina dominante ha venido constriñendo la teoría de la simulación al campo contractual. Sin embargo, esta apriorística limitación contrasta con la realidad de los hechos, que nos muestran la forma en que la simulación escapa del terreno contractual para irrumpir en el ámbito total de la vida. Dicha simulación es producto de un impulso instintivo del hombre, ratificado después racionalmente como eficaz instrumento para la vida en sociedad a la cual está llamado.

Resulta innegable que el campo contractual sea el lugar donde la simulación juega mayor relevancia, pues es allí donde precisamente su utilización trae aparejadas las consecuencias jurídicas para las partes y los terceros involucrados. Esta razón justifica que la doctrina se haya ocupado de la simulación contractual con cierta preferencia, 
pues la misma surgió desde el derecho romano, cuando existía discrepancia de las voluntades. Además, a partir de ella se disponía de la apariencia de un negocio real, mediante la celebración de otro que se utilizaba de fachada (Morffi Collado y Galiano Maritan, 2014, p. 180).

La simulación es la declaración de una voluntad no real, previo acuerdo entre las partes, con el fin principal de aparentar un acto jurídico que no existe, o es distinto de aquel que realmente se ha llevado a cabo. Por esta razón, existirían dos actos y dos voluntades: a) el realizado para simular la existencia de otro, con una declaración contraria a la deseada, que es la que se exterioriza; y b) el acto que se pretende realizar a través del encubrimiento del primero, donde la voluntad no se declara, pero es perseguida por las partes.

En el negocio simulado intervienen dos declaraciones de voluntad. Por un lado, la simulada, aquella que se manifiesta y, por otro lado, la disimulada, aquella en la que las partes pueden acordar no celebrar ningún contrato, o celebrar uno diferente al manifestado por las partes. En el caso de la voluntad simulada se produce la simulación absoluta del negocio jurídico, en la que el rol del negocio simulado consiste en servir como medio necesario para conseguir la simulación, y no tiene como fin ocultar el acuerdo simulatorio.

En la simulación relativa, por el contrario, el fin del negocio simulado es ocultar el disimulado o sus elementos para, de esta forma, lograr que los efectos que se han exteriorizado pertenezcan a un negocio distinto al que realmente pertenecen (Aguilar Guerra, 2006, p. 226).

La simulación del negocio jurídico tiene como principal consecuencia la nulidad del acto. Para el Código Civil cubano (1987), se consideran nulos todos los actos realizados por medio de la simulación, sea esta absoluta o relativa. Por un lado, se identifica la simulación absoluta cuando el acto se efectúa solo en apariencia, sin intención de producir efectos jurídicos (Ley 59, 1987, art. 67, inc. e). Por otro lado, la simulación es relativa cuando el acto se realice con el propósito de encubrir otro acto diferente, es decir, el que será válido para las partes si concurren los requisitos esenciales para su validez (Ley 59, 1987, art. 67, inc. f) (Pinto Oliveros, 2016, p. 32).

La simulación relativa no versa siempre sobre los mismos elementos del negocio, sino que puede recaer sobre el precio; sobre la fecha del negocio; sobre el disfraz de una de las partes para aparentar la intervención de una persona diferente, que es lo que se conoce en la práctica como simulación por interposición de persona; o cuando realizan un negocio simulado, ocultando el que realmente es deseado por las partes, conocido como negocio disimulado.

El contrato de donación es considerado como el más legítimo de los actos gratuitos y, por ende, uno de los tipos contractuales más sui generis de los conocidos 
en la doctrina, mientras exhibe la calificación de paradigma de las liberalidades. Estas razones son suficientes para que sea utilizado como negocio aparente que oculta un negocio oneroso, en este caso un contrato de compraventa. En estos supuestos existe la intención de engañar y no una intención fraudulenta, porque en la simulación no se persigue necesariamente un fin ilícito, pues no faltan supuestos de simulación en que se engaña sin una intención manifiesta de perjudicar'. El animus nocendi no es un elemento de la simulación, como sí lo es, en cambio, el animus decipiendi.

La cuestión, una vez simulado el contrato de donación, sería determinar si la compraventa encubierta será válida en caso de resultar nula la escritura pública de donación que le sirve de máscara, o si esa misma escritura, en la que formalizaron la donación, servirá para darle validez a la compraventa disimulada.

En ese caso, serán las partes interesadas las que puedan aportar los medios de prueba correspondientes y, si faltaran las pruebas exigidas del contrato disimulado, habrá que declarar la nulidad del contrato de compraventa a tenor de lo dispuesto en el inciso e del artículo 67 del Código Civil cubano. En este sentido, demuestra, en caso contrario, su licitud y el cumplimiento de los requisitos establecidos ex lege para su validez y eficacia, contractus simulatus valet se-cundum id, quod actum est, si eo modo valere possit .

Para ello, es necesario acudir a la vía judicial en pos de declarar la nulidad del negocio simulado, y dejar indemne el disimulado si concurren en él los requisitos esenciales que le confieren valor jurídico, con el objetivo de garantizar la seguridad jurídica como principio del derecho.

En este orden, la simulación de los negocios jurídicos trasciende al momento actual en el marco del derecho civil y el derecho de contratos, premiados por los ya no tan recientes cambios que introdujeron el Decreto-Ley 288 (2011), modificativo de la Ley 65 (1988) o Ley General de la Vivienda, y el Decreto 320 (2013), este presenta las regulaciones para la transmisión de la propiedad de vehículos automotor. Estas normas pueden dar paso a la simulación de los negocios jurídicos y, en especial, del contrato de donación, objeto de la presente investigación.

Si bien la simulación de los negocios jurídicos existió desde la Roma antigua, constituye una realidad que, ante la promulgación de los mencionados decretos, se comienzan a proliferar casos de simulación de donaciones. Estos casos anteriormente, por razones prohibitivas, ocurrían con otros negocios jurídicos, por ejemplo, se simulaba un contrato de permuta que encubría una compraventa de viviendas, compraventa que anteriormente se prohibía por la Ley General de la Vivienda (1988), salvo que el comprador fuera el Estado.

En tal sentido, el presente artículo tiene como objetivo sistematizar los presupuestos teóricos y normativos fundamentales de la simulación de la donación, a partir

El animus nocendi no es un elemento de la simulación, sí lo es, en cambio, el animus decipiendi. 
del estudio de la simulación de los negocios jurídicos, con el fin de analizar la posible validez de los contratos de compraventa disimulados tras un contrato de donación.

El trabajo quedará estructurado en dos partes a través de varios epígrafes que se relacionan entre sí. La primera se dedicará al estudio doctrinal de la simulación en los contratos traslativos del derecho de propiedad, los requisitos del negocio disimulado y la forma que adquiere el contrato de donación aparente y compraventa encubierta. Y, en la segunda, se abordará el tema de la prueba en las donaciones simuladas por las partes y los terceros interesados; lo cual se realizará a partir del análisis jurisprudencial que sustenta el objeto de la investigación, lo cual permitirá formular de manera adecuada las conclusiones como respuesta al objetivo plantado en el trabajo. Por último, se enlistan las referencias bibliográficas utilizadas.

\section{LA SIMULACIÓN EN LOS CONTRATOS TRASLATIVOS DEL DERECHO DE PROPIEDAD}

Los contratos de compraventa, permuta y donación son tipos contractuales que tienen como principal objeto trasmitir el derecho de propiedad (Delgado Vergara y Galiano Maritan, 2018, p. 2). Por ello, se consideran especies contractuales que pueden servir de cauce para simular un contrato de compraventa o de permuta, a través de una donación; o una permuta a través de una compraventa; o una compraventa a través de una permuta. De esta manera, se origina una apariencia jurídica sobre determinado bien, razón para que sean utilizados como negocios aparentes que ocultan un contrato de compraventa o de permuta ${ }^{2}$.

Una vez simulado el contrato de donación o permuta, habría que determinar si la compraventa encubierta será válida en caso de resultar nula la escritura pública otorgada, que le sirve de máscara, o si esa misma escritura, en la que formalizaron uno u otro contrato, servirá para darle validez a la compraventa disimulada. En este caso, serán las partes interesadas las que puedan aportar los medios de prueba correspondientes y, si faltaran las pruebas exigidas del contrato disimulado, habrá que declarar la nulidad del contrato a tenor de lo dispuesto en el inciso $e$ del artículo 67 del Código Civil cubano (1987). En caso contrario, se demuestra su licitud y el cumplimiento de los requisitos establecidos ex lege para su validez jurídica.

\subsection{Definición de donación simulada}

La simulación de la donación se define como aquel acuerdo de voluntades en el cual las partes contratantes (donante y donatario) acuerdan un supuesto contrato de donación, en el que simulan la entrega aparente y gratuita de la propiedad de un bien a otra persona, formándose consecuentemente un negocio distinto al querido por las partes. Todo esto, si se entiende la simulación del negocio jurídico como la

La permuta puede ser disimulada, en ciertos casos y por determinadas circunstancias, a través de una donación o a través de una compraventa. 
divergencia entre la declaración de voluntad negocial y la voluntad de las partes en el negocio, con el fin de aparentar un negocio que no existe, o es diferente al que se realiza realmente (Morffi Collado y Galiano Maritan, 2014, p. 183).

En Cuba, con la promulgación del Decreto-Ley 288 (2011), modificativo de la Ley 65 (1988) que permitió la libre donación de viviendas formalizada en el instrumento público notarial, previa inscripción en el registro de la propiedad, el negocio que las partes simulan es un contrato de donación y el negocio disimulado es una compraventa.

Las partes utilizan la donación como negocio aparente por las propias características de este contrato. En primer lugar, porque constituye, por excelencia, una liberalidad (Pérez Gallardo y Galiano Maritan, 2016, p. 49), y ello propicia que las partes evadan la obligación fiscal establecida en la Resolución 351 (2011) del Ministerio de Finanzas y Precios. Para la donación, el pago del impuesto es del $4 \%$ solo para el donatario, como parte del impuesto sobre transmisión de bienes y herencias. En la compraventa se exige para ambas partes, vendedor y comprador, uno como parte del impuesto sobre ingresos personales, en este caso el vendedor; por otro lado, en el caso del comprador, se exige por el impuesto sobre transmisión de bienes y herencias.

En segundo lugar, se utiliza la donación, porque las partes se evitan una serie de trámites exigidos ex lege para la realización de la compraventa, que no se exigen para el contrato de donación. Aquí nos referimos a la entrega del cheque de gerencia como instrumento de pago correspondiente emitido por una institución bancaria, el cual será entregado en el acto de formalización ante el notario para su posterior cobro y para la declaración sobre la licitud de los fondos, con independencia del importe. De esta manera, queda el banco exonerado de cualquier responsabilidad al respecto, y el documento queda acreditativo de la entidad bancaria de que no posee deudas por concepto de vivienda en el banco.

Por último, la falta de un asesoramiento legal adecuado a las partes sobre los efectos jurídicos patrimoniales de cada contrato una vez que se formalicen, con lo cual tributan al control de la legalidad; a la prevención de posibles litigios; y a que los sujetos cumplan con las obligaciones que se deriven de sus actos.

La realidad vivida en nuestro país desde la promulgación del mencionado Decreto-Ley 288 (2011), demuestra la forma en la que el número de donaciones autorizadas es superior en gran medida a las compraventas. En este sentido, no se aprecia, de la lectura de los primeros, que exista entre las partes vínculos de consanguinidad o afinidad, al menos que se narre en el instrumento. Además, aunque con ello no se puede afirmar que las personas estén ciertamente simulando las donaciones que realizan, realmente resulta cuestionable que el mayor número de personas se inclinen por un acto de causa liberal de gratuidad, antes que por uno 
de los actos más frecuentes en el tráfico jurídico y económico, reconocidos desde Roma hasta la actualidad, como es el contrato de compraventa.

Un estudio realizado en la provincia de Ciego de Ávila (Cuba) demuestra la veracidad de lo afirmado. En el año 2011, con la apertura del mencionado Decreto-Ley, se realizaron setenta y dos compraventas de inmuebles y doscientas cuarenta donaciones; seguidamente en el 2012 se efectuaron seiscientas sesenta y nueve compraventas y mil novecientas tres donaciones; y en el 2013 se tramitaron setecientas cincuenta y ocho compraventas y mil quinientas setenta y una donaciones; y en el 2014 hasta el mes de junio, se realizaron quinientas veintiuna compraventas y ochocientas ocho donaciones. El anterior análisis nos conduce a afirmar que la diferencia es sustancial, pero si se analizan las restricciones existentes antes del Decreto-Ley 288 (2011), se podría justificar que en el primer año y en el siguiente, todo el que haya realizado cualquier trámite sobre compraventa de viviendas se dedicaba a actualizar sus títulos. Sin embargo, la cifra se mantuvo superior desde el 2011 hasta la actualidad.

Si se analizan las disposiciones anteriores, en relación con lo que está sucediendo en el país, se considera plausible evitar que las personas continúen simulando los negocios que realizan, sin saber las consecuencias que puede ocasionar para los terceros, e incluso para ellas mismas. En este sentido, las personas generan inseguridad jurídica y, además, el notario queda libre de responsabilidad después de haber plasmado en la escritura una cláusula sobre la coincidencia que debe existir entre la declaración interna con la que se exterioriza (Corzo González, 2009, p. 9).

Aunque la Ley 50 (1984) no distinguió el modo de formular las advertencias por parte del notario actuante, sino que tan solo se limitó al empleo del vocablo "hacer", la práctica ha demostrado la necesidad de que se consigne en el otorgamiento de la escritura, todas las advertencias que procedan según el acto jurídico que se formalice, y las indicaciones que en sede notarial se indiquen por la Dirección de Notarías y Registros Civiles del Ministerio de Justicia.

Sin embargo, ello atenta contra el principio de autoría y redacción, función que le corresponderá al notario al momento de redactar el texto del instrumento. De esta manera, el notario le impregna su impronta y sello personal, además, adecúa siempre los intereses de las partes a las disposiciones legales que rigen el acto de que se trate. No obstante, la redacción de los documentos públicos, aunque debe ajustarse a la estructura normativa regulada en la legislación notarial, debe ser creativa y flexible, teniendo como principal objetivo redactar la voluntad de las partes y darle forma según las regulaciones establecidas para cada contrato.

Lo explicado anteriormente obliga al notario a dejar constancia en el documento de algo que quizás las partes no deseaban, o simplemente ni siquiera habían pensado. De esta manera, se conspira contra la satisfacción de los intereses civiles privados y contra la autonomía de la voluntad que la ley reconoce a las partes. 


\subsection{Requisitos del negocio disimulado}

Para probar la eficacia del negocio disimulado, se deben cumplir determinados requisitos para que el acto superviva a la declaración de ineficacia del negocio simulado. En ese sentido, se pueden mencionar los siguientes:

- Se deberá probar la existencia del acto disimulado mediante la apariencia del acto a título gratuito, es decir, que ciertamente se celebró un contrato de compraventa y se cumplieron los requisitos establecidos para su validez, según el Decreto-Ley 288 (2011) y las normas establecidas en el Código Civil cubano.

- Que los requisitos de fondo del acto disimulado sean cumplidos para que nada impida su validez, siempre y cuando reúna los requisitos esenciales para su constitución, y las partes así lo hayan deseado.

Una vez examinados los requisitos del negocio disimulado, se impone la necesidad de probar su existencia, para lo cual los interesados deberán aportar las pruebas necesarias. En ese sentido, se encuentran las presunciones, tal y como lo establece el artículo 353 de la Ley de Procedimiento Civil, Administrativo, Laboral y Económico (1977).

En el supuesto de que faltaran las pruebas del negocio disimulado, se tendrán en cuenta las reglas establecidas para la simulación absoluta, y se declarará nulo el negocio a tenor de lo regulado en el inciso $e$ del artículo 67 del Código Civil cubano (1987), que establece la nulidad de los actos jurídicos realizados solo en apariencia, sin intención de producir efectos jurídicos. De lo contrario, solo quedaría comprobar que los requisitos exigidos para la validez de la compraventa disimulada sean los propios a su naturaleza, es decir, que cumpla con los requisitos necesarios para su validez.

La exigencia de que la compraventa disimulada reúna todos los requisitos personales, reales y formales exigidos en la regulación de las compraventas descubiertas, plantea cuestiones relativas a la forma3:

La libertad de forma constituye la regla general, y será indispensable emplear una forma determinada: 1) cuando la ley lo exija como elemento esencial, imponiéndola ad substantitam, bajo pena de nulidad, y no ad probationem o solo por vía de prueba; y 2) cuando las partes contratantes establezcan la exigencia de una forma determinada ad substantiam. (Hernández Betancourt, 2010, p. 95)

Por ello, se analizará seguidamente la forma del contrato de compraventa encubierto tras una donación.

3 La libertad de forma es el principio que rige en el sistema contractual cubano, artículo 50 en relación con el 313 del Código Civil (1987) cubano; en el Código Civil (1888) español se regula en el artículo 1278, el Código Civil de Puerto Rico lo regula en el artículo 1230, y el Código Civil (1966) portugués en el artículo 219. 


\subsection{La forma en el contrato de donación aparente y en la compraventa encubierta}

Los contratos formales son aquellos en los cuales la ley exige que la voluntad sea exteriorizada bajo el cumplimiento de determinada forma, denominada ad probationem. Cuando esa forma no sea cumplida, el acto o contrato no producirá plenos efectos jurídicos. En cambio, los contratos solemnes son aquellos en los cuales la ley exige que la voluntad se constituya como un requisito de existencia o validez, ad solemnitatem, es decir, de obligatorio cumplimiento, pues en caso de no cumplirse, el contrato no tendrá validez alguna (Galiano Maritan y Trujillo Ribot, 2012, p. 14).

En el caso del contrato de donación, la forma puede visualizarse desde tres aristas fundamentales: a) la verbal, aquella en la que los bienes donados son de carácter mueble y la cuantía no debe ser superior a los requisitos establecidos por las normas, en dependencia del ordenamiento jurídico que se trate; b) la escrita, dentro de la cual se ubican las donaciones de bienes muebles; y c) las donaciones realizadas bajo el requisito de escritura pública notarial, ya sea de bienes muebles o inmuebles, en dependencia del valor del bien donado (Barreto Muga, 1995, p. 195).

La posibilidad verbal o de escritura de los bienes muebles está dada por la cuantía de lo donado. Sin embargo, la donación de bienes inmuebles siempre se hará por escrito con respecto a la cuantía determinada por ley, por lo tanto, será un documento privado o una escritura pública (Zamora y Valencia, 1994, p.133).

A contrario sensu, la escritura pública constituye un requisito de validez para las donaciones de bienes inmuebles, así como para las prestaciones periódicas o vitalicias, es decir, constituye un requisito ad solemnitaten, con excepción de aquella realizada a favor del Estado (Borda, 1999, p. 311; Costas Rodal, 2012, pp. 21-29).

La aceptación de la donación podrá realizarse de forma expresa o tácita en la misma escritura pública de donación. No obstante, en el caso de las donaciones de bienes muebles, se podrán realizar mediante un documento privado o mediante la mera tradición de la cosa, invalidando la promesa verbal.

Sin embargo, aun cuando existan diversas opiniones, también existen criterios entre los que se establecen semejanzas. Por ejemplo, cuando se expresa que si los bienes donados fuesen de carácter mueble podrá hacer de dos formas: verbal (si se entrega la cosa simultáneamente) o escrita (Lacruz Berdejo, 1986, p. 121; Díez Picazo, 1989, p. 341).

En el caso de la donación verbal, la entrega de la cosa es fundamental para que exista el contrato mismo (Lacruz Berdejo, 1986, p. 122). En el supuesto de que los objetos donados sean bienes inmuebles, deberá constar siempre en escritura pública para que tenga validez (Díez Picazo, 1989, p. 341). 
En el Código Civil cubano (1987) se establece que la donación respecto a los bienes muebles podrá realizarse de forma verbal o escrita. En el caso de la forma verbal, se exige la entrega simultánea de lo donado, y en caso de no ser así, deberá constar por escrito al igual que la aceptación (Decreto 320, 2013).

Para el caso de los bienes inmuebles, siempre se realizará mediante documento público, en el cual también deberá constar la aceptación. Si el destinatario es una entidad estatal, no se tendrá en cuenta la naturaleza de lo donado, pues el contrato siempre se hará mediante documento público.

La traditio en la donación de bienes inmuebles en el Código Civil cubano asume una forma instrumental que trae consigo la transmisión del dominio, pero ello no significa que exista una traditio de carácter genuino. El contrato de donación cuando adquiere cuerpo mediante una escritura pública notarial, trae implícita la incorporación a dicho documento del consenso traslativo expuesto por las partes. La autorización de la mencionada escritura pública es el equivalente a la entrega de los bienes objeto de la donación, por lo que el donatario será el titular del dominio de estos, aunque no se haya llevado a cabo el desplazamiento posesorio real (Pérez Gallardo, 2010, p. 80).

\section{T41.3.1 El requisito de forma en el contrato de compraventa encubierta}

El Código Civil cubano establece en el artículo 339 que la compraventa de bienes inmuebles se formaliza en documento público y su validez está condicionada al cumplimiento de los demás requisitos legales. Este precepto se relaciona con el artículo 191 del propio texto legal, que en el segundo apartado impone la sanción de nulidad a las transmisiones que se realicen sin la autorización o las formalidades requeridas (Delgado Vergara, 2014, p. 45).

De lo anterior se colige que el legislador cubano en la redacción de sus preceptos le imprimió el carácter de solemne a la compraventa en Cuba, y no solo a ella, sino también a la donación. Sin embargo, el legislador, en su redacción, olvidó la presencia y redacción del artículo 313 del Código Civil cubano, en el cual, cuando las partes así lo decidan, pueden compelerse a cumplir las formalidades establecidas siempre que exista el consentimiento y los demás requisitos necesarios para su validez.

Por ello, resulta necesario analizar si la escritura pública de donación sería necesaria para otorgar validez a la compraventa disimulada en ese propio instrumento público, una vez declarada la nulidad de la donación que le sirve de máscara.

En la anterior situación, resulta claro que la escritura de donación, en la cual consta la voluntad de donar y la aceptación del donatario, no cumple con el requisito de acuerdo entre el vendedor y el comprador sobre el bien objeto de la venta y el precio.

A pesar de ello, autores como Vallet de Goytisolo (1972, p. 678) y Tobeñas (1955, p. 540) consideran válido el negocio disimulado si es lícito y reúne los requisitos propios 
a su naturaleza especial. De esta manera, exigen que se demuestre el origen del acto ocultado requerido por las partes, y el cumplimiento de los requisitos impuestos por la ley, en la que la escritura de donación sería nula cuando faltase la voluntad de donar y la aceptación del donatario (García Vicente, 2017, p. 84).

Si el negocio simulado no se realiza ante un notario público, correría peligro ante la imposibilidad de ser alertado el donante-vendedor de los inconvenientes que pudieran aparecer tras celebrar el negocio, en el cual quedaría privado de protección jurídica, no solo él, sino también los terceros involucrados en el negocio. No obstante, la ausencia de advertencias legales no es razón suficiente para declarar nula la compraventa disimulada tras una donación simulada.

Los actos celebrados con la finalidad de encubrir otros producen la nulidad del negocio fantasma. De esta manera, dejan indemne el negocio disimulado siempre que cumpla los requisitos de validez y eficacia, cuando las partes así lo consientan y cuando respeten la forma que, en mi opinión, no sufre laceración alguna (Moratilla Galán, 2005, p. 1075).

Comparto el criterio de Fernández Martell (2012), lo que se concibe nulo en todo caso es el acto jurídico contenido en la forma, no la escritura pública en sí. Esto es así porque el notario que autoriza el acto no ha incumplido con las exigencias de elaboración del documento y, además, no están presentes las causales de nulidad de los instrumentos públicos notariales. Si en caso contrario tuviera lugar, sí se vería en desventaja tanto la forma como el contenido, por ser de los actos que requieren de la forma ad substantiam como elemento de validez (Fernández Martell, 2012, p. 288).

Una vez descubierto el negocio simulado, su estructura sirve de sostén al negocio disimulado, por tanto, la escritura pública quedaría reservada como elemento de validez y eficacia a la compraventa disfrazada, la que necesita de la forma ad solemnitatem para su subsistencia.

La compraventa de inmuebles exige la forma notarial para surtir efectos jurídicos en el ordenamiento civil cubano, considerándose un contrato solemne. En esta medida, el legislador debió tener en cuenta el comentado artículo 313 del Código Civil cubano, del cual se puede interpretar que el contrato siempre existirá cuando haya consentimiento, y la forma es solo un medio de prueba o un requisito para su eficacia, que conecta a ambos contratos. En el caso de la donación de bienes inmuebles, en su artículo 374.1, y para la compraventa de inmuebles en el artículo 339, ambos del referido cuerpo legal.

Resulta pertinente llamar la atención sobre la última parte de los preceptos enunciados cuando remiten la validez de ambos contratos (donación y compraventa) al cumplimiento de las disposiciones legales, para el caso de inmuebles, las reguladas en la Ley 65 (1988) con las modificaciones que introdujo el Decreto-Ley 288 (2011). En 
su lugar, se admite la compraventa de viviendas entre personas naturales de conjunto a otros actos de dominio, como la permuta y la donación. Pero, coincidentemente entre la compraventa y la donación, la ley especial consigna que los interesados formalicen ante fedatario público este acuerdo de voluntades, siendo la escritura pública el documento idóneo para materializar la forma exigida ex lege.

La escritura pública de donación simulada no puede ser utilizada para una de compraventa disimulada por ser contrario el contenido a la realidad de la calificación del instrumento. No obstante, si se tiene en cuenta que las partes han simulado el acto, habrá que delimitar los requisitos del negocio aparente para darle validez al negocio encubierto, siempre que así lo deseen los interesados (Vallet de Goytisolo, 1972, p. 700; Castro y Bravo, 2002, p. 275). Estos negocios tienen un elemento común esencial para su perfección, la forma -en este caso como forma de ser ad solemnitatem y no de valer ad probationem - que deberán cumplir según los artículos 374.1 (donación de inmuebles) y 339 (compraventa de inmuebles) del Código Civil cubano.

El negocio encubierto será válido si cumple con los requisitos legales exigidos, pero tendrá que mudar de traje. La escritura como vestidura exterior del acto tiene que cambiar y adaptarse a las medidas que le sirven al verdadero negocio realizado por las partes.

La compraventa encubierta tras una donación simulada tipifica un supuesto de simulación relativa, así lo establece el artículo 67, en su inciso f. No obstante, a pesar de declarar nulo los actos realizados con el propósito de encubrir otro acto distinto, se admite la validez del negocio disimulado si concurren en él los requisitos esenciales que le confieren valor jurídico.

Si se analiza esta segunda parte del inciso, lo que se consideraría válido es el negocio en sí, siempre que concurran en él los requisitos exigidos para su validez. Sin embargo, esa afirmación no debe considerarse extensiva al documento público donde se formaliza el negocio jurídico, pues aun cuando la ley no distingue entre la escritura de donación y la de compraventa, sí existen regulaciones específicas para la configuración de cada negocio jurídico en particular.

\section{LA PRUEBA EN LAS DONACIONES SIMULADAS POR LAS PARTES Y LOS TERCEROS INTERESADOS}

La simulación tiene como objetivo principal la elaboración artificiosa de una apariencia engañosa que se destina a ocultar la verdad. Por tanto, para poder demostrar la simulación, será necesario instituir medios probatorios idóneos que prueben que ha ocurrido el acuerdo simulatorio, para que puedan hacerse valer sus efectos, tanto internos como externos. En el negocio simulado, generalmente se tratan de cumplir, aunque aparentemente, los requisitos externos de legalidad y seriedad. En esa medida, todas las partes eliminan las huellas y crean una verdadera apariencia (Castro y Bravo, 1985, p. 366). 
De allí que lo revelador sea la dificultad de aportar las pruebas de la simulación, pues las partes simulantes tratan de acomodar la apariencia artificiosa. Este es un resultando complicado para que los terceros logren percibir y demostrar lo real (Garcés Vásquez, 2014, p. 96).

En ese sentido, el que alegue judicialmente la divergencia entre dos elementos que normalmente se armonizan, tiene que probarlo, pues los supuestos anormales no se presumen (Verdela y Tuells, 1950, p. 593). Concierne, por ende, la prueba de la simulación a quién pretenda obtener algún beneficio real de la invalidación, o a aquella persona sobre quien reclama, siguiendo el principio del onus probandi incumbit actoris (Ley 7, 1977, art. 244).

Vale destacar, además, que en esta sede todos los medios de prueba, tanto típicos como atípicos, se podrán emplear para demostrar la simulación del negocio aparente. En tal sentido, los elementos que se pueden utilizar son los siguientes:

El contradocumento o contradeclaración (contre-lettres), como aquel instrumento público o privado acordado entre las partes, en el que declaran el contenido o fin real del acto simulado (Rivera, 1994, p. 804). Generalmente, este instrumento está destinado a permanecer en secreto, pues constituye un excelente medio de prueba para demostrar que la apariencia ficticia del negocio ha sido conveniada.

En caso de faltar el contradocumento, para surtir efecto probatorio, existen medios alternativos como la confesión de los simulantes, que son los que en definitiva conocen el acuerdo simulatorio, mediante el cual se puede reconocer la apariencia con la que fue realizada el negocio. Se debe recordar que en nuestro ordenamiento jurídico la confesión tiene un valor pleno o tasado.

Las presunciones de simulación, denominadas también presunciones de hecho, solo se admitirán cuando el hecho del que han de deducirse esté completamente acreditado, y cuando entre el hecho demostrado y aquel que se trate de deducir exista una relación específica según las reglas del criterio racional. Si falta la prueba de la existencia de un negocio disimulado, habrá que aplicar las consecuencias de la simulación absoluta.

La prueba de la causa simulandi constituye el conjunto de razones que indujeron a las partes a celebrar el negocio ficticio, mientras mostraban la razón y los motivos de la simulación. Descubrir ese motivo tiene gran importancia porque proyecta una luz esclarecedora sobre todo negocio y facilita la interpretación de la conducta de las partes. La causa simulandi es de difícil prueba porque los motivos que tuvieron las partes son inciertos, imprecisos, ambiguos y de contornos indefinidos, especialmente cuando las partes han tratado de ocultarlo y han puesto en ello todo su ingenio.

La posición ambigua presenta la prueba testifical, la cual no es admitida, pues solo las partes conocen realmente la voluntad que tenían en el momento de constitución 
del negocio. En este caso, los jueces, ante las manifestaciones acusatorias de las partes, deberán atender las pruebas irrefutables alegadas, pues en derecho se exige que las apariencias valgan como realidad. Para precaver este resultado, las partes, casi siempre, tienen la previsión de hacer constar el hecho de la simulación y sus propósitos.

Para que proceda la protección de los terceros en la simulación se deben cumplir determinados requisitos, pues la simulación no se demuestra por sí misma. En ese sentido, se identifican los siguientes:

1. La existencia de un derecho adquirido por un tercero que posee el título viciado por la simulación. En este caso, la simulación en sí no establece el reconocimiento de los derechos que hubieran nacido de ser verdadero el negocio simulado (Castro y Bravo, 2002, p. 380).

2. La buena fe de las partes. En este supuesto, será el juez el encargado de clarificar todos los datos aportados para valorar la conducta de las partes con arreglo a las circunstancias del caso que le permitan determinar si actuaron de buena fe (Ojeda Rodríguez, 2013, p. 104).

A contrariis, si el tercero invoca la simulación respecto de otro tercero que pretende prevalerse de esta, entonces si tiene interés en determinar la buena o mala fe con la que aquel tercero actúa.

Por tanto, en nuestro criterio, cuando se suscite un conflicto de intereses entre terceros, tendrá preferencia el tercero que de buena fe invoca el contrato aparente. Un conflicto de intereses se puede presentar cuando uno de ellos quiera aprovecharse de la apariencia creada por el contrato simulado, y el otro se quiera aprovechar de la realidad resultante del desenmascaramiento de la verdad.

\section{LA ACCIÓN DE NULIDAD POR SIMULACIÓN Y LOS SUJETOS LEGITIMADOS PARA EJERCERLA}

La acción de simulación tiene como único objetivo desenmascarar la verdad. En este sentido, se constituye como una acción autónoma ejercida por aquel que persigue, mediante su pretensión, la declaración con fuerza de la cosa juzgada de nulidad del contrato aparente o simulado. Así, esta acción es declarada por la mayoría de la doctrina como una acción de declaración de certeza, cuyo objetivo principal es reconocer judicialmente la nulidad del acto simulado y que, como consecuencia de ello, queden desvanecidos los efectos que al mismo se le imputaban (Castro y Bravo, 1985, p. 366; Ojeda Rodríguez, 2001, p. 133; Llambías, 1977, p. 461; Borda, 1999, p. 1181 ; Cifuentes, 1995, p. 180; Mélich Orsini, 2012, pp. 867-875).

El interés que legitima al actor para intentar la acción de simulación está radicalmente determinado por el interés de la acción principal a la que ella va adosada. Por tanto, ese interés conlleva a clasificar la acción de simulación como una acción 
personal, pues el petitum es siempre el reconocimiento de la realidad desfigurada por el acto aparente (Rengel Romberg, 1992, p. 367).

En tal sentido, se pueden identificar las siguientes peculiaridades de la acción de simulación:

1. La acción de simulación despliega un derecho propio, ejercido por quien dispone de un régimen probatorio que es diferente según la posición que tenga en la relación, es decir, que sea parte o tercero en relación con el acuerdo simulatorio. Con la acción de simulación se trata de comprobar que el contrato es ficticio, porque el mismo no ha modificado la situación jurídica precedente, o tal modificación no es la reflejada por el contrato simulado.

2. La acción de simulación está a disposición de cualquiera que pueda tener interés en desenmascarar la realidad que oculta el contrato ficticio. Por tanto, la acción puede ser ejercida tanto por las propias partes, como por cualquier tercero, aunque se trate o no de un acreedor propiamente, siempre y cuando invoque un interés jurídico cierto en acreditar la simulación.

De una u otra forma, queda abierto el camino para una acción de condena, preferentemente la que más interese al demandante, mientras se considere una acción constitutiva (Cifuentes, 1995, p. 380), y exista la posibilidad de pedir acumuladamente la acción declarativa de simulación, para que el mismo juez que declare inválido el acto simulado, disponga la medida judicial pertinente.

A la acción de simulación también se une la acción revocatoria o pauliana, aquella acción subsidiaria para solicitar que se declare simulado el acto que se denuncia como aparente y, en el caso de no ser un negocio aparente, puede ser revocado por fraude de acreedores (Cifuentes, 1995, p. 381).

La acción pauliana se encuentra regulada en el inciso $g$ del artículo 111 del Código Civil cubano. Allí se denomina como una acción revocatoria y se le concede un carácter subsidiario. Pero el inciso c del artículo 76 establece que son rescindibles los actos realizados de manera válida por los deudores en fraude de acreedores. De esta manera, le otorga un carácter rescisorio a la acción pauliana.

De una u otra forma, queda abierta la posibilidad para que pueda interponerse una acción de condena, como la única que le puede interesar al demandante, por ejemplo, las acciones restitutorias, reivindicatorias, entre otras. En estos casos, la acción también tiene el objetivo de eliminar cualquier obstáculo que haya surgido en el ejercicio del derecho, como una tercería de dominio, mejor derecho, concurrencia y prelación de créditos, entre otras (Castro y Bravo, 2002, p. 381).

La acción de simulación puede ser promovida por las partes o por terceros. En este sentido, puede ser ejercitada por una de las partes contra terceros y viceversa. 
De esta manera, cuando la acción de simulación se ejerce por uno de los autores de la simulación contra el otro para obtener la declaración de nulidad del contrato, mediante la cual se realizó la transmisión de la propiedad de su inmueble, es evidente que se busque la tutela del derecho de propiedad sobre el inmueble. Así, de este derecho, nace el interés legítimo de remover la apariencia del contrato por medio de la acción de simulación que asume el carácter de acción real en este caso.

En este caso, la acción también puede ser ejercitada contra un tercero, siempre que se compruebe que este trata de valerse de una apariencia que creía que no se correspondía con la realidad, lo cual lo convertiría en un tercero de mala fe.

En tal caso, resulta indiferente determinar si el tercero que declara la simulación contra las partes ha conocido o no la naturaleza simulada del contrato impugnado en el momento en que las partes lo fingieron. La razón es que solo se trata de establecer la realidad del contrato simulado y de darle cabida al principio general de oponibilidad de los contratos. En el supuesto de que el tercero invoque la simulación respecto de otro tercero que aspira a servirse de esta, será necesario determinar la buena o mala fe con la que aquél tercero actúa.

Por tanto, resulta oportuno dejar establecido que, en caso de conflicto de intereses entre terceros, tendrá preferencia el tercero que de buena fe haya invocado el contrato aparente. Dicho conflicto se presenta cuando uno de los terceros quiere aprovecharse de la apariencia creada por el contrato simulado, mientras el otro quiere aprovecharse de la realidad resultante del desenmascaramiento de la verdad, en aplicación de la teoría de la apariencia (Castro y Bravo, 2002, p. 359).

Una vez ejercida la acción contra la simulación, la demanda debe interponerse contra todos los participantes en el acuerdo simulatorio. En otras palabras, deben acudir todos los que hayan participado en el procedimiento de simulación, o que, aun siendo extraños, se hayan beneficiado con ella.

Por último, en el ejercicio de la acción deben intervenir todos los sujetos que participaron en la celebración del negocio simulado, caracterizándose por ser una acción indivisible o erga omnes. En este caso, los efectos no se limitan a las partes que intervienen en el proceso, sino que se extienden tanto a los terceros, como a los acreedores que no lo iniciaron, es decir, a aquellos que se beneficiarían con la declaración de simulación (Cifuentes, 1995, p. 382).

Como es sabido, la acción de simulación no tiene una naturaleza pública, por ende, su ejercicio se encuentra limitado para ser ejercido por los contratantes simulantes y sus herederos; por los terceros ajenos a la simulación o por aquellos que, como consecuencia, sufren un perjuicio o dejan de tener un beneficio conforme a un derecho ya adquirido. 
En esa medida, apremia la necesidad de analizar los requisitos de la acción para ejercerla ante los tribunales. Los requisitos pueden ser sustantivos y formales. Dentro de estos últimos, es importante destacar los que se refieren a la legitimación activa y a la legitimación pasiva. La legitimación activa constituye un recurso importante para los herederos y legitimarios. Esto se debe a que los herederos tienen su campo de acción restringido cuando tienen algún motivo sobre el negocio encubierto por estar obligado a respetar los actos propios del causante. Además, solo podrá impugnar los actos del causante cuando los realicen en ejercicio de acciones que hubiera podido realizar el propio causante y que ahora, como heredero, le asistirían en virtud de la transmisión sucesoria (Vallet de Goytisolo, 1972, p. 726).

Los legitimados activos en el proceso podrán demandar a todas aquellas personas que sean partes en el negocio y a sus causahabientes, ya sea a título hereditario, o por cualquier otro título en los derechos que se pretenden nacidos del negocio impugnado. Además, también podrán demandar a cualquier persona que se ampare jurídicamente en el negocio que se trata de impugnar.

Visto así, sería oportuno preguntarse: ¿Quién estará legitimado para impugnar la donación simulada por el causante, sin que ello constituya un supuesto de venire contra factum propio?

En este caso, el heredero voluntario o legal será el que tenga capacidad, sustantiva y procesal, para impugnar la donación simulada por el causante (Fernández Martell, 2012, p. 304). En esta situación, el heredero sí podría ejercer la acción luego de la muerte del causante y podrá impugnar, no solo el negocio jurídico simulado, sino también el disimulado, siempre que entienda que ese acto nació contrario a la ley, o que, aunque nació en el tráfico jurídico, después se hizo ineficaz con el consiguiente ejercicio de una acción.

El legitimario, por su parte, podrá dirigirse contra la compraventa disimulada, en el caso de la simulación absoluta, y, posteriormente, se podrá dirigir a la donación simulada siempre y cuando por la realización de tal acto merme su porción legitimaria (Pérez Gallardo, 2007, pp. 180-181). Para ello, debe ampararse en el principio de intangibilidad cuantitativa de la legítima, porque, en este caso, sus derechos no nacen de la voluntad del testador, sino de la propia norma legal que se los otorga, sin posibilidad de desconocérselos. Esto se debe a que, a diferencia de los herederos voluntarios, aquellos, por esa única cualidad, no son continuadores en la titularidad de las relaciones jurídicas del de cuius, independientemente del vínculo que para otros efectos lo vinculen con el causante de la sucesión. En consecuencia, no se encuentran limitados por el principio venire contra factum proprium non valet, que implicaría la imposibilidad de atacar los actos simulados en los que figure el causante, por considerarlos como propios, en cuanto los actos que realiza vinculan a sus herederos. 
Por tanto, la titularidad de la acción de impugnación de los actos viciados por esta causa le viene atribuida a los legitimarios por el carácter imperativo y protector de las normas que regulan el instituto sucesorio, independientemente del título de atribución de la legítima. En este sentido, se considera un tercero interesado en la impugnación.

La acción de simulación puede guardar estrecha relación con acciones como la revocatoria y la subrogatoria, denominadas de recomposición del patrimonio (Ojeda Rodríguez, 2001, p. 130). Estas acciones tienen un interés práctico para obtener la pretensión de los acreedores, cuya única exigencia es que el actor alegue y pueda comprobar un interés personal tutelado por el ordenamiento jurídico, y no por una expectativa de derecho.

No obstante, en varias ocasiones, la acción de simulación sirve de instrumento a la revocatoria y, por ende, ambas pueden acumularse a fin de probar si el acto es incierto o fraudulento. De esta manera, se procedería a declarar la nulidad absoluta o su consecuente rescisión por fraude de acreedores (Sentencia 499/16, 2016).

\section{CONCLUSIONES}

La simulación de una donación de inmuebles, que encubre una compraventa, constituye un supuesto de simulación relativa que vulnera el principio de la seguridad jurídica, toda vez que se crea una apariencia negocial; se evade el fisco; se pueden ver afectados los terceros que confiaron en la celebración del negocio; y se generan falsos efectos, lo que afecta a la sociedad en su conjunto y, de igual forma, a la coherencia del sistema económico-jurídico.

En el segundo apartado del inciso f en el artículo 67 del Código Civil cubano, a pesar de declarar nulos los actos realizados con el propósito de encubrir otro acto distinto, se admite la validez del negocio disimulado si concurren en él los requisitos esenciales que le confieren valor jurídico. No obstante, tal afirmación no alcanza al documento público, pues para cada negocio existen diferencias formales en su configuración y, por tanto, no puede considerarse válida la compraventa disimulada en escritura pública de donación, sino que deberá otorgarse una nueva escritura pública para dotar de eficacia a la compraventa.

No existe previsión normativa en cuanto a los terceros que, de buena fe, hayan confiado en la apariencia real del negocio. Este reconocimiento es necesario si se tiene en cuenta que la simulación tiene como principal fin el engaño a terceros cuyo acto simulado ignoraban, los cuales deberán acudir al amparo de la interpretación jurisprudencial.

La compraventa disimulada se considerará válida siempre que cumpla con los requisitos esenciales del contrato, a tenor del artículo 313 del Código Civil (1987) cubano. De esta manera, cuando exista constancia de haber intervenido el consentimiento y 
los demás requisitos necesarios para su validez, las partes podrán compelerse recíprocamente al otorgamiento de una nueva escritura, esta vez en correspondencia con el negocio efectivamente realizado.

El ejercicio de la acción contra la simulación es un requisito para obtener la declaración de nulidad de la donación simulada y, además, abrir el cauce a la validez de la compraventa disimulada, siempre que esta reúna los verdaderos requisitos que la conforman. Con ello, se contribuirá a perfeccionar la labor de los jueces en el proceso dirigido a obtener la nulidad del acto jurídico simulado, en el que la fase probatoria es esencial. Esto, para que el tribunal pueda llegar a la convicción de que la probada existencia de tales hechos resulta incompatible según las experiencias prácticas con la realidad aparente, para lo cual podrá utilizar todos los medios de prueba reconocidos en el derecho.

\section{REFERENCIAS}

Aguilar Guerra, V. (2006). El negocio jurídico (5. a ed.). Guatemala, 2006.

Asamblea Nacional Constituyente. (1966, 26 de noviembre). Código Civil de la República de Portugal [vigente desde 1967]. Diario da República (Separata), 2008-10-31, núm. 212.

Asamblea Nacional del Poder Popular de la República de Cuba (1977, 19 de agosto). Ley 7 de 1977. Ley de Procedimiento Civil, Administrativo, Laboral y Económico. Editorial Pueblo y Educación.

Asamblea Nacional del Poder Popular de la República de Cuba (1984, 28 de diciembre). Ley 50 de 1984. Ley de las Notarías Estatales, Minjus.

Asamblea Nacional del Poder Popular de la República de Cuba (1987, 16 de julio). Ley 59 de 1987. Código Civil de la República de Cuba. Divulgación del Minjus. https://www.wipo.int/edocs/lexdocs/ laws/es/cu/cu005es.pdf

Barreto Muga, A. (1995). Manual teórico práctico del derecho de los contratos civiles y mercantiles. Fecat.

Borda, G. A. (1999). Tratado de derecho civil. Parte general, Tomo II. Abeledo Perrot.

Castro y Bravo, F. (2002). El negocio jurídico (1. a ed.). Editorial Civitas.

Cifuentes, S. (1995). Elementos del derecho civil, parte general (4. ${ }^{\text {a }}$ ed.). Astrea.

Consejo de Estado (2011, 28 de octubre). Decreto-Ley 288 de 2011 (modificativo de la Ley 65 de 1988 o Ley General de la Vivienda]. Gaceta Oficial extraordinaria n. ${ }^{\circ}$ 35, 2 de noviembre de 2011.

Consejo de Estado (2011, 2 de noviembre). Resolución 351/2011, Gaceta Oficial Extraordinaria n. ${ }^{\circ}$ 035 de 2 de noviembre de 2011, Ministerio de Justicia

Consejo de Estado (2013, 31 de diciembre). Decreto 320 de 2013. Gaceta Oficial Extraordinaria n. ${ }^{\circ} 046$ de la República de Cuba. Ministerio de Justicia.

Corzo González, L. J. (2009). Principios del derecho notarial cubano. En L. B. Pérez Gallardo, Derecho notarial (pp. 9-20). Editorial Félix Varela.

Costas Rodal, L. (enero de 2012). Forma del contrato de donación y simulación. Revista Doctrinal Arazandi Ciil-Mercantil, 1(9), 21-29. https://dialnet.unirioja.es/servlet/articulo?codigo $=4078747$ 
Delgado Vergara, T. (2014). El contrato de compraventa de vivienda en Cuba. Anuario Iberoamericano de Derecho Notarial, 2-3, 33-56. http://www.notariado.org/liferay/c/document_library/get_ file?uuid=5297c 128-fa75-4328-bbb8-d5fb19ebad81 EgroupId = 10218

Delgado Vergara, T., y Galiano Maritan, G. (2018). El contrato de compraventa. En G. Galiano Maritan (ed.), Los contratos en el Código Civil de Ecuador (pp. 1-428). Reus. Biblioteca Iberoamericana de Derecho.

Díez Picazo, L. (1989). Sistema de derecho civil. El contrato en general. La relación obligatoria. Contratos en especial. Cuasi contratos. Enriquecimiento sin causa. Responsabilidad extracontractual (6. ${ }^{a}$ ed., vol. 2). Editorial Tecnos.

Fernández Martell, J. (2012). Compraventa simulada. Apuntes desde la protección jurídica de los terceros involucrados. En L. B. Pérez Gallardo, La compraventa como paradigma contractual (1. ${ }^{\text {a ed. }}$ ) (pp. 288-304). Rubinzal-culzoni editores.

Galiano Maritan, G., y Trujillo Ribot, Y. (2012, octubre). La donación. pautas teóricas doctrinales que norman su contenido. Derecho y Cambio Social(30), 1-24.

Garcés Vásquez, P. A. (2014). Formas de manifestación del consentimiento y su eventual tergiversación: la simulación. Revista Nuevo Derecho, 10(15), 89-98. http://revistas.iue.edu.co/revistasiue/index.php/ nuevoderecho/article/view/651

García Vicente, J. (2017). La simulación de los contratos en la jurisprudencia del Tribunal Supremo. Thomson Reuters Arazandi.

Hernández Betancourt, Y. (2010). La donación de inmueble ¿Contrato solemne o tan solo formal? En L. B. Pérez Gallardo, Contratos gratuitos (pp. 93-107). Temis, Ubijus, Reus, y Zavalía.

Lacruz Berdejo, J. E. (1986). Derecho de Obligaciones, Contratos y Cuasicontratos (2. ${ }^{a}$ ed., vol. 3). José María Bosch.

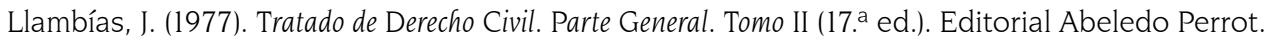

Mélich Orsini, J. (2012). Doctrina General del Contrato (5. a ed., vol. 1). Editorial Sabias Palabras, C.A.

Ministerio de Gracia y Justicia (1888, 6 de octubre). Código Civil del Reino de España (24. a ed.) Editorial Tecnos.

Moratilla Galán, I. (2005). Nulidad del contrato de venta: presunción de la simulación de la inexistencia de dicho contrato. Revista Crítica de Derecho Inmoviliario,81(689), 1075. https://dialnet.unirioja.es/ servlet/articulo?codigo $=2969490$

Morffi Collado, C., y Galiano Maritan, G. (2014). La simulación como causa de ineficacia jurídica en el Código Civil cubano. Revista de Derecho Privado(27), 179-214. https://www.redalyc.org/ pdf/4175/417537013009.pdf

Ojeda Rodríguez, N. (2001). Defensa y protección del crédito. En N. y. Ojeda Rodríguez, Teoría General de las obligaciones. Comentarios al Código Civil cubano (pp. 124-149). Editorial Félix Varela.

Ojeda Rodríguez, N. (2013). Comentario al artículo 6 del Código Civil cubano. En L. B. Pérez Gallardo, Comentarios al Código Civil cubano. Disposiciones preliminares, Libro Primero, Relación Jurídica (Vol. I) (pp. 91-110). Editorial Félix Varela.

Pérez Gallardo, L. B. (2010). La donación en el Código Civil cubano: ¿Contrato con eficacia promisoria o dispositiva? Notas para atizar una polémica. En L. Pérez Gallardo, Contratos Gratuitos (pp. 531549). Temis, Ubijus, Reus y Zavalía. 
Pérez Gallardo, L. B. (2007). Los herederos especialmente protegidos. La legítima. Defensa de su intangibilidad cualitativa y cuantitativa. En L. B. Pérez Gallardo, Derecho de Sucesiones (vol. 2) (pp. 69-198). Editorial Félix Varela.

Pérez Gallardo, L. B., y Galiano Maritan, G. (2016). Contrato gratuito del derecho de propiedad: La donación. En N. Ojeda Rodríguez, Derecho de Contratos, Tomo II, Contratos en especie y responsabilidad contractual. Parte I (pp. 1-475). Editorial Félix Varela.

Pinto Oliveros, S. (2016). Breves notas críticas sobre la simulación en el Código Civil peruano a la luz del derecho comparado. Themis: Revista de Derecho(70), 31-41. http://revistas.pucp.edu.pe/index. php/themis/article/view/19600

Rengel Romberg, A. (1992). Tratado de Derecho Procesal Civil según el nuevo Código de 1978 (vol. 1). Arte.

Rivera, J. (1994). Instituciones del derecho civil. Parte general. Abeledo Perrot.

Sala de lo civil y lo administrativo del Tribunal supremo de Cuba. (2016, 30 de junio). Sentencia 499/16 de 2016 (Valdés Rosabal, M. P.).

Tobeñas, C. (1955). Derecho civil español, común y foral. Introducción y Parte general. Teoría de la Relación Jurídica $y$ los derechos subjetivos. Los derechos de la personalidad (9. ${ }^{\text {a }}$ ed., vol. 2).Editorial Reus.

Vallet de Goytisolo, J. (1972). Las donaciones de bienes inmuebles disimuladas según la jurisprudencia del Tribunal Supremo. Anuario de Derecho Civil, 25(3), 678-726.

Verdela y Tuells, V. (1950). Algunos aspectos de la simulación. Anuario de Derecho Civil, 3 (1), 28-52.

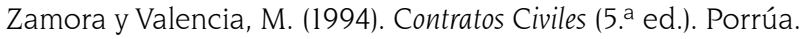

